\title{
ANALISIS KECACATAN PRODUK CRUDE PALM OIL (CPO) MENGGUNAKAN METODE QUALITY CONTROL CIRCLE (QCC) PADA PT.RAMAJAYA PRAMUKTI
}

\author{
St.Nova Meirizha, Dian Kristina \\ Program Studi Teknik Industri, Fakultas Teknik, Universitas Muhammadiyah Riau \\ Jalan Tuanku Tambusai Ujung, Kecamatan Tampan, Kelurahan Delima, Kota Pekanbaru, Riau 28291 \\ Email: novameirizha@umri.ac.id, $170103041 @$ student.umri.ac.id
}

\begin{abstract}
Quality is the overall characteristics and characteristics of a product or service whose ability to satisfy needs, both expressed and implied (Irwan \& Haryono, 2015). In this era of increasingly competitive industrialization, every business person who wants to win the competition in the industrial world will pay full attention to quality. QCC is a new concept to improve the quality and productivity of industrial/service work. It is evident that one of the success factors of industrialization in Japan is the effective implementation of QCC. In this research journal, the quality of crude palm oil (CPO) levels is decreasing. There are 3 types of defects, namely levels of FFA (Free Fatty Acids), levels of Moisture (Water) and levels of Dirt (Stool). Of these three, the most dominant are FFA levels and Moisture levels. Free fatty acid content (FFA) of 158 samples tested contained 150 samples of free fatty acids (FFA) which were outside the company standard. Then followed by moisture content with a total defect of 45 samples from 158 test samples. At the level of dirt (Dirt) there are absolutely no samples that are outside the company's standards.
\end{abstract}

Keywords: Quality Control Circle (QCC), Crude Palm Oil (CPO), Quality, Total Quality Management $(T Q M)$

\section{Abstrak}

Kualitas merupakan keseluruhan ciri dan karakteristik produk atau jasa yang kemampuannya dapat memuaskan kebutuhan, baik yang dinyatakan secara tegas maupun tersamar (Irwan \& Haryono, 2015). Dalam era industrialisasi yang semakin kompetitif sekarang ini, setiap pelaku bisnis yang ingin memenangkan kompetisi dalam dunia industri akan memberikan perhatian penuh pada kualitas. QCC adalah salah satu konsep baru untuk meningkatkan mutu dan produktivitas kerja industri / jasa. Terbukti bahwa salah satu faktor keberhasilan industrialisasi di Jepang adalah penerapan QCC secara efektif. Dalam jurnal penelitian ini kualutas kadar pada crude palm oil (CPO) kian menurun. Terdapat 3 jenis kecacatan yaitu kadar FFA (Asam Lemak Bebas), kadar Moisture (Air) dan kadar Dirt (Kotoran). Dari ketiga ini yang sangat mendominan adalah kadar FFA dan kadar Moisture. kadar asam lemak bebas (FFA) dari 158 sampel pengujian terdapat 
150 sampel asam lemak bebas (FFA) yang berada diluar standar perusahaan. Selanjutnya disusul oleh kadar air (Moisture) dengan jumlah kecacatan 45 sampel dari 158 sampel pengujian. Pada kadar kotoran (Dirt) sama sekali tidak ada sampel yang berada diluar standar perusahaan.

Kata Kunci: Quality Control Circle (QCC), Crude Palm Oil (CPO), Kualitas, Total Quality Management (TQM)

\section{Pendahuluan}

PT.Ramajaya Pramukti, Rama-Rama Mill, KCP, dan Biogas di bawah naungan PT. SMART Corporation Jakarta bergerak di bidang industri minyak kelapa sawit. Sebagai produk luarannya adalah CPO (Crude Palm Oil) dan PKO (Palm Kernel Oil). Selama masa pengolahan, tidak sedikit kendala atau permasalahan sering terjadi. Salah satu nya adalah masalah kecacatan pada Crude Palm Oil (CPO) yang dilihat dari kenaikan Kadar Asam Lemak Bebas atau FFA (Free Fatty Acid) dan tingkat Kadar Air (Moisture) yang berada diluar standar perusahaan. Standar yang ditetapkan oleh PT.Ramajaya Pramukti untuk Crude Palm Oil (CPO) yaitu untuk kadar asam lemak bebas (Free Fatty Acid/FFA) maksimal $3 \%$, kadar air (Moisture) maksimal $0.15 \%$, dan kadar kotoran (Dirt) maksimal 0.03\%. Berdasarkan data histori perhari yang dimiliki perusahaan menampilkan kenaikan kadar asam lemak bebas (Free Fatty Acid/FFA) dan kadar air (Moisture) yang mengakibatkan penurunan kualitas Crude Palm Oil (CPO) dan akan mempengaruhi pada kepuasan konsumen/pelanggan. Berikut adalah data histori perhari perusahaan setelah hasil pengujian sampel Crude Palm Oil (CPO) yang dilakukan oleh unit laboratorium pada tanggal 7 September 2020 hingga 10 Oktober 2020 yaitu:
Tabel 1.1. Data Histori Rata-Rata Hasil Pengujian Parameter Crude Palm Oil (CPO)

\begin{tabular}{|c|c|c|c|c|}
\hline \multirow{4}{*}{ No } & \multirow{4}{*}{ Hari/Tanggal } & \multirow{2}{*}{\multicolumn{3}{|c|}{$\begin{array}{c}\text { Parameter CPO } \\
\text { Standar Perusahaan }\end{array}$}} \\
\hline & & & & \\
\hline & & $\begin{array}{c}\text { Kadar Asam } \\
\text { Lemak Bebas } \\
\text { (Free Fatty Acid) } \\
\% \\
\end{array}$ & $\begin{array}{c}\text { Kadar Air } \\
\text { (Moisture) \% }\end{array}$ & $\begin{array}{c}\text { Kadar } \\
\text { Kotoran } \\
\text { (Dirt) \% }\end{array}$ \\
\hline & & $\leq 3 \%$ & $\leq 0.150 \%$ & $\leq 0.03 \%$ \\
\hline 1 & Senin, 07 September 2020 & 3.75 & 0.16 & 0.016 \\
\hline 2 & Selasa, 08 September 2020 & 3.77 & 0.17 & 0.016 \\
\hline 3 & Rabu, 09 September 2020 & 3.19 & 0.16 & 0.015 \\
\hline 4 & Kamis, 10 September 2020 & 3.04 & 0.18 & 0.016 \\
\hline 5 & Jumat, 11 September 2020 & 3.74 & 0.17 & 0.017 \\
\hline 6 & Sabtu, 12 September 2020 & 4.06 & 0.17 & 0.018 \\
\hline 7 & Senin, 14 September 2020 & 3.78 & 0.18 & 0.019 \\
\hline 8 & Selasa, 15 September 2020 & 3.21 & 0.19 & 0.019 \\
\hline 9 & Rabu, 16 September 2020 & 3.13 & 0.21 & 0.020 \\
\hline 10 & Kamis, 17 September 2020 & 3.52 & 0.15 & 0.018 \\
\hline 11 & Jumat, 18 September 2020 & 3.99 & 0.15 & 0.019 \\
\hline 12 & Sabtu, 19 September 2020 & 4.31 & 0.15 & 0.019 \\
\hline 13 & Senin, 21 September 2020 & 4.62 & 0.14 & 0.020 \\
\hline 14 & Selasa, 22 September 2020 & 4.68 & 0.14 & 0.020 \\
\hline 15 & Rabu, 23 September 2020 & 4.41 & 0.14 & 0.017 \\
\hline 16 & Kamis, 24 September 2020 & 4.67 & 0.16 & 0.016 \\
\hline 17 & Jumat 25 September 2020 & 4.90 & 0.14 & 0.016 \\
\hline 18 & Sabtu, 26 September 2020 & 4.91 & 0.16 & 0.018 \\
\hline 19 & Senin, 28 September 2020 & 4.85 & 0.14 & 0.018 \\
\hline 20 & Selasa, 29 September 2020 & 4.35 & 0.13 & 0.019 \\
\hline 21 & Rabu, 30 September 2020 & 4.11 & 0.13 & 0.019 \\
\hline 22 & Kamis, 01 Oktober 2020 & 5.27 & 0.13 & 0.019 \\
\hline 23 & Jumat, 02 Oktober 2020 & 4.05 & 0.13 & 0.018 \\
\hline 24 & Sabtu, 03 Oktober 2020 & 3.92 & 0.16 & 0.019 \\
\hline 25 & Senin, 05 Oktober 2020 & 4.16 & 0.13 & 0.076 \\
\hline 26 & Selasa, 06 Oktober 2020 & 4.06 & 0.13 & 0.018 \\
\hline 27 & Rabu, 07 Oktober 2020 & 4.16 & 0.30 & 0.018 \\
\hline 28 & Kamis, 08 Oktober 2020 & 4.14 & 0.25 & 0.017 \\
\hline 29 & Jumat, 09 Oktober 2020 & 3.60 & 0.14 & 0.018 \\
\hline 30 & Sabtu, 10 Oktober 2020 & 3.23 & 0.14 & 0.064 \\
\hline
\end{tabular}

Dari data tersebut, maka dapat dilihat parameter pengujian Crude Palm Oil (CPO) pada kadar asam lemak bebas (Free Fatty Acid/FFA) dan kadar air (Moisture) sering melebihi atau diluar standar yang telah ditetapkan oleh perusahaan. Hal ini akan merugikan perusahaan apabila tidak ada tindakan lanjutan sebagai upaya preventif yang berkelanjutan. Untuk itu perlu dilakukun analisis kecacatan Crude Palm Oil (CPO).

\section{Implementasi Metode}


Implementasi Metode Quality Control Circle (QCC) Pada Analisis Kecacatan Crude Palm Oil (CPO) Pt. Ramajaya Pramukti. QCC adalah salah satu konsep baru untuk meningkatkan mutu dan produktivitas kerja industri / jasa. Terbukti bahwa salah satu faktor keberhasilan industrialisasi di Jepang adalah penerapan QCC secara efektif. Karena keberhasilan ini, sejumlah negara industri maju dan sedang berkembang termasuk Indonesia, menerapkan QCC diperusahaanperusahaan industri guna meningkatkan mutu, produktivitas dan daya saing. Dalam pelaksanaannya, QCC terdiri dari 7 atau 8 langkah yang berdasarkan siklus P-D-C-A (Plan-Do-Check-Action) secara berkesinambungan.

Tahapan dalam penelitian ini dapat dilakukan dengan langkah-langkah berikut:

1. Identifikasi Jumlah Kecacatan.

Dalam mengumpulkan data dan mengidentifikasi jumlah kecacatan, seven tools yang digunakan adalah Check Sheet (Lembar Pemeriksaan).

2. Identifikasi Frekuensi Kecacatan

Untuk mengetahui frekuensi kecacatan lebih jelas mulai dari frekuensi kecacatan tertinggi hingga terendah dapat menggunakan Histogram.

3. Monitoring dan Evaluasi pada Batas Kendali

Langkah selanjutnya yaitu memonitor dan mengevaluasi suatu aktivitas / proses berada dalam pengendalian kualitas yang akan memecahkan masalah dan menghasilkan perbaikan kualitas menggunakan Peta Kendali (Control Chart).

4. Usulan Perbaikan (Rekomendasi).

Langkah selanjutnya adalah usulan perbaikan (rekomendasi) yang menggunakan siklus PDCA (Plan, Do, Check dan Action) dalam memberikan masukan untuk perusahaan sebagai upaya perbaikan.

\section{Hasil dan Pembahasan}

1. Identifikasi Jumlah Kecacatan

Pada check sheet ini, penganalisis data yang disajikan dalam bentuk tabel yang berisi data jumlah sampel yang diuji dan jenis kecacatan Crude Palm Oil (CPO) beserta dengan jumlahnya.

Tabel 3.1. Check Sheet Analisis Kecacatan pada Paramater CPO

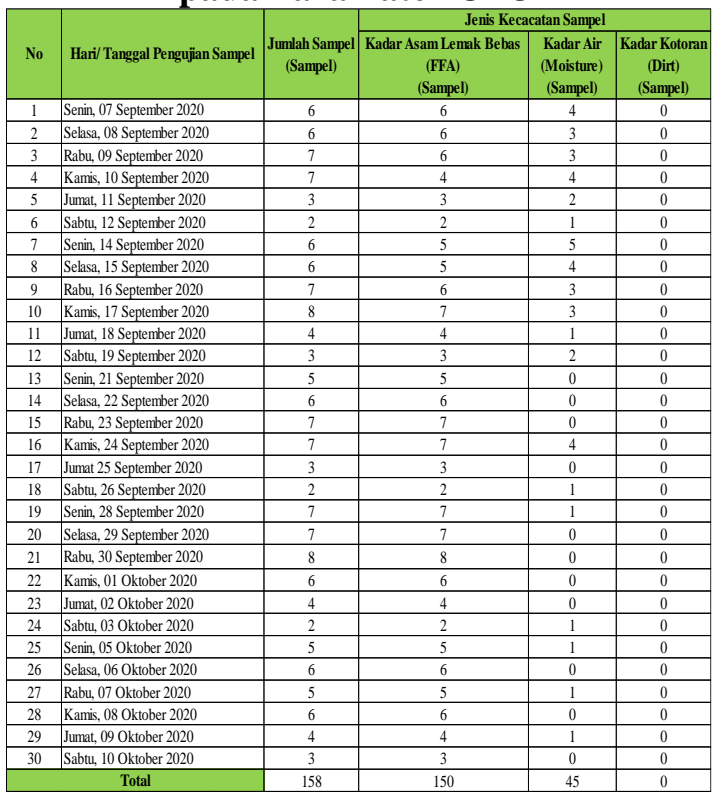

Dari data Check Sheet diatas maka dapat dilihat jenis kecacatan sampel tertinggi yaitu kadar asam lemak bebas (FFA) dari 158 sampel pengujian terdapat 150 sampel asam lemak bebas (FFA) yang berada diluar standar perusahaan. Selanjutnya disusul oleh kadar air (Moisture) dengan jumlah kecacatan 45 sampel dari 158 sampel pengujian. Pada kadar kotoran (Dirt) sama sekali tidak ada sampel yang berada diluar standar perusahaan.

2. Identifikasi Frekuensi Kecacatan

Berikut adalah tabel dan histogram analisis kecacatan pada parameter CPO yaitu: 
Tabel 3.2. Klasifikasi Jenis Kecacatan CPO

\begin{tabular}{|c|l|c|}
\hline $\begin{array}{c}\text { N } \\
\text { o }\end{array}$ & \multicolumn{1}{|c|}{ Jenis Cacat } & $\begin{array}{c}\text { Jumlah } \\
\text { (Sampel) }\end{array}$ \\
\hline 1 & $\begin{array}{l}\text { Kadar Asam Lemak } \\
\text { Bebas (FFA) }\end{array}$ & 150 \\
\hline 2 & Kadar Air (Moisture) & 45 \\
\hline 3 & Kadar Kotoran (Dirt) & 0 \\
\hline \multicolumn{2}{|c|}{ Total } & 195 \\
\hline
\end{tabular}

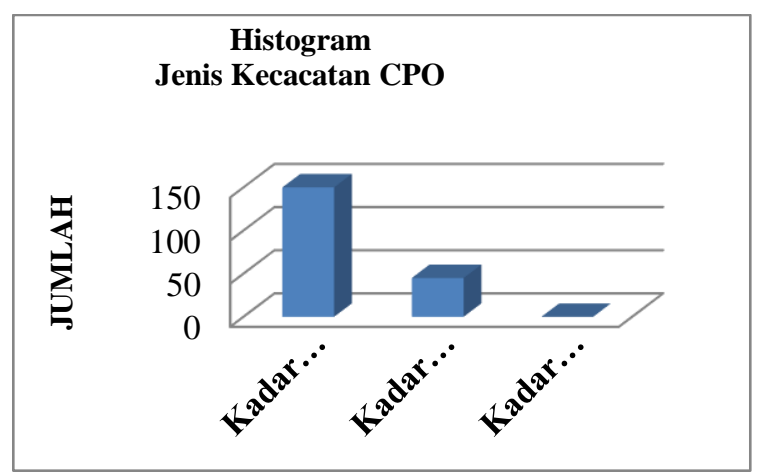

Gambar 3.1. Histogram Analisis Kecacatan CPO

3. Monitoring dan Evaluasi pada Batas Kendali.

Adapun peta kendali pada analisis kecacatan CPO kadar asam lemak bebas (FFA) dan kadar air (Moisture) sebagai berikut:

Tabel 3.3. Perhitungan Batas Kendali Kecacatan pada Kadar Asam Lemak Bebas

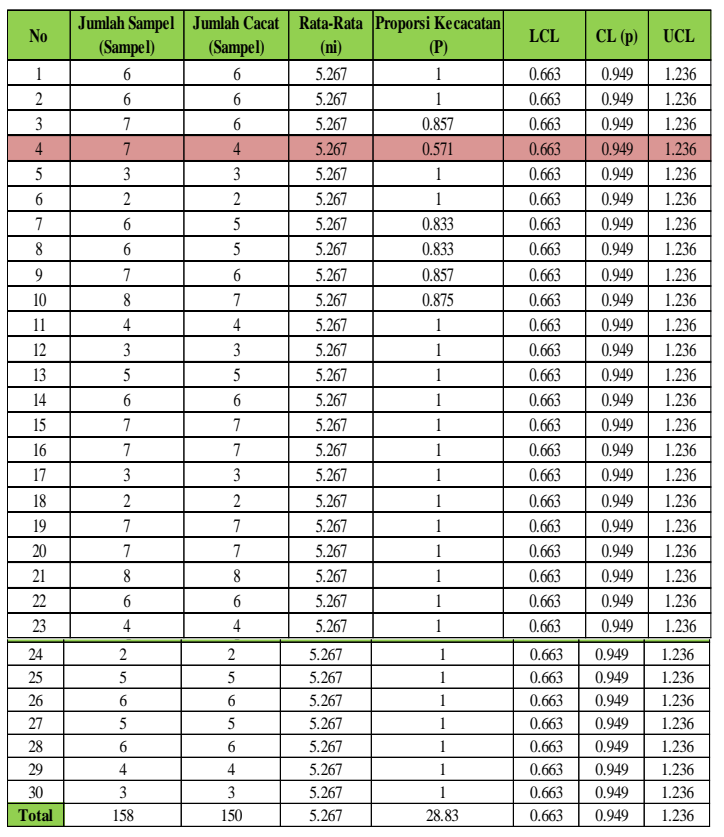

Berikut adalah langkah-langkah dalam membuat peta kendali $\mathrm{p}$ (control chart) yaitu:

a. Menghitung proporsi kecacatan

$\mathrm{P}=\mathrm{np} / \mathrm{n}$

Keterangan:

$\mathrm{P}=$ Proporsi Kecacatan

$\mathrm{np}=$ Jumlah Cacat

$\mathrm{n}=$ Jumlah Sampel

Contoh perhitungan diatas adalah:

$$
\mathrm{P}=\mathrm{np} / \mathrm{n}=6 / 6=1
$$

b. Menghitung garis pusat/Central Line (CL)

$\mathrm{CL}=\left(\sum \mathrm{np}\right) /\left(\sum \mathrm{n}\right)$

Keterangan:

$\mathrm{CL}=$ Central Line

$\sum \mathrm{np}=$ Total Cacat dalam 1 bulan

$\sum \mathrm{n}=$ Total Sampel dalam 1 bulan

Contoh perhitungan diatas :

$\mathrm{CL}=\left(\sum \mathrm{np}\right) /\left(\sum \mathrm{n}\right)=150 / 158=0.949$

c. Mengitung batas kendali atas/ Under

Control Limit (UCL)

$\mathrm{UCL}=\mathrm{CL}+3 \sqrt{ }(\mathrm{p}(1-\mathrm{p})) / \mathrm{ni}$

$\mathrm{UCL}=0.949+3 \sqrt{ }(0.949(1-0.949)) / 5.267$

$\mathrm{UCL}=1.236$

d. Menghitung batas kendali bawah/ Lower

Control Limit (LCL)

$\mathrm{UCL}=\mathrm{CL}-3 \sqrt{ }(\mathrm{p}(1-\mathrm{p})) / \mathrm{ni}$ 


$$
\begin{aligned}
\mathrm{UCL} & =0.949-3 \sqrt{ }(0.949(1-0.949)) / 5.267 \\
\mathrm{UCL} & =0.663
\end{aligned}
$$

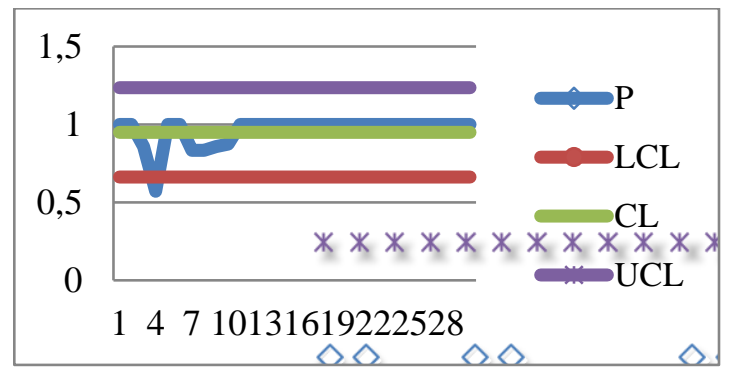

Gambar 3.2. Peta Kendali Kecacatan FFA

Selanjutnya adalah perhitungan dan diagram peta kendali $\mathrm{p}$ pada kadar air (moisture) pada Crude Palm Oil (CPO) yaitu:

Tabel 3.4. Perhitungan Batas Kendali Kecacatan pada Kadar Moisture

\begin{tabular}{|c|c|c|c|c|c|c|c|}
\hline No & $\begin{array}{c}\text { Jumlah Sampel } \\
\text { (Sampel) }\end{array}$ & $\begin{array}{c}\text { Jumlah Cacat } \\
\text { (Sampel) }\end{array}$ & Rata-Rata (ni) & Proporsi Kecacatan (P) & LCL & CL (p) & UCL \\
\hline 1 & 6 & 4 & 5.267 & 0.667 & -0.305 & 0.285 & 0.875 \\
\hline 2 & 6 & 3 & 5.267 & 0.500 & -0.305 & 0.285 & 0.875 \\
\hline 3 & 7 & 3 & 5.267 & 0.429 & -0.305 & 0.285 & 0.875 \\
\hline 4 & 7 & 4 & 5.267 & 0.571 & -0.305 & 0.285 & 0.875 \\
\hline 5 & 3 & 2 & 5.267 & 0.667 & -0.305 & 0.285 & 0.875 \\
\hline 6 & 2 & 1 & 5.267 & 0.500 & -0.305 & 0.285 & 0.875 \\
\hline 7 & 6 & 5 & 5.267 & 0.833 & -0.305 & 0.285 & 0.875 \\
\hline 8 & 6 & 4 & 5.267 & 0.667 & -0.305 & 0.285 & 0.875 \\
\hline 9 & 7 & 3 & 5.267 & 0.429 & -0.305 & 0.285 & 0.875 \\
\hline 10 & 8 & 3 & 5.267 & 0.375 & -0.305 & 0.285 & 0.875 \\
\hline 11 & 4 & 1 & 5.267 & 0.250 & -0.305 & 0.285 & 0.875 \\
\hline 12 & 3 & 2 & 5.267 & 0.667 & -0.305 & 0.285 & 0.875 \\
\hline 13 & 5 & 0 & 5.267 & 0.000 & -0.305 & 0.285 & 0.875 \\
\hline 14 & 6 & 0 & 5.267 & 0.000 & -0.305 & 0.285 & 0.875 \\
\hline 15 & 7 & 0 & 5.267 & 0.000 & -0.305 & 0.285 & 0.875 \\
\hline 16 & 7 & 4 & 5.267 & 0.571 & -0.305 & 0.285 & 0.875 \\
\hline 17 & 3 & 0 & 5.267 & 0.000 & -0.305 & 0.285 & 0.875 \\
\hline 18 & 2 & 1 & 5.267 & 0.500 & -0.305 & 0.285 & 0.875 \\
\hline 19 & 7 & 1 & 5.267 & 0.143 & -0.305 & 0.285 & 0.875 \\
\hline 20 & 7 & 0 & 5.267 & 0.000 & -0.305 & 0.285 & 0.875 \\
\hline 21 & 8 & 0 & 5.267 & 0.000 & -0.305 & 0.285 & 0.875 \\
\hline 22 & 6 & 0 & 5.267 & 0.000 & -0.305 & 0.285 & 0.875 \\
\hline 23 & 4 & 0 & 5.267 & 0.000 & -0.305 & 0.285 & 0.875 \\
\hline 24 & 2 & 1 & 5.267 & 0.500 & -0.305 & 0.285 & 0.875 \\
\hline 25 & 5 & 1 & 5.267 & 0.200 & -0.305 & 0.285 & 0.875 \\
\hline 26 & 6 & 0 & 5.267 & 0.000 & -0.305 & 0.285 & 0.875 \\
\hline 27 & 5 & 1 & 5.267 & 0.200 & -0.305 & 0.285 & 0.875 \\
\hline 28 & 6 & 0 & 5.267 & 0.000 & -0.305 & 0.285 & 0.875 \\
\hline 29 & 4 & 1 & 5.267 & 0.250 & -0.305 & 0.285 & 0.875 \\
\hline 30 & 3 & 0 & 5.267 & 0.000 & -0.305 & 0.285 & 0.875 \\
\hline T0TAL & 158 & 45 & 5.267 & 8.92 & -0.305 & 0.285 & 0.875 \\
\hline & & & & & & & \\
\hline
\end{tabular}

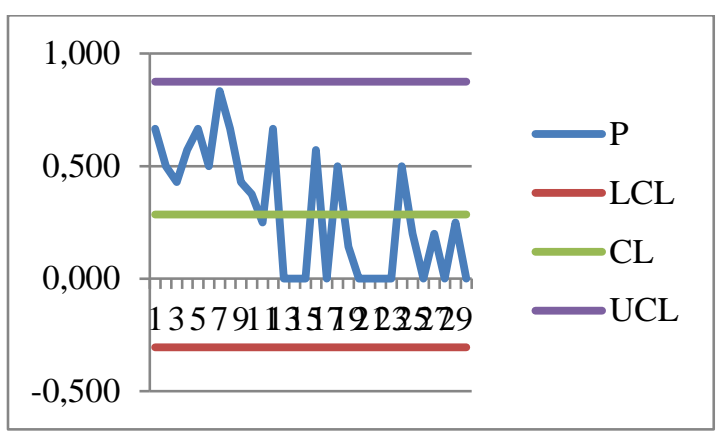

Gambar 3.3. Peta Kendali Kecacatan

\section{Moisture}

4. Usulan Perbaikan (Rekomendasi)

Langkah selanjutnya adalah usulan perbaikan (rekomendasi) yang menggunakan siklus PDCA (Plan, Do, Check dan Action) dalam memberikan masukan untuk perusahaan sebagai upaya perbaikan atau pencegahaan mengenai kecacatan pada parameter CPO.

a. Tahapan Plan (Perencanaan)

Adapun beberapa langkah-langkah dalam melakukan tahapan plan yaitu:

1. Menentukan pokok masalah dan menganalisa masalah yang terjadi.

2. Menentukan Penyebab Masalah

Berikut adalah fishbone (diagram sebab-akibat) pada kecacatan CPO PT.Ramajaya Pramukti pada kadar FFA dan Kada Moisture yaitu: 


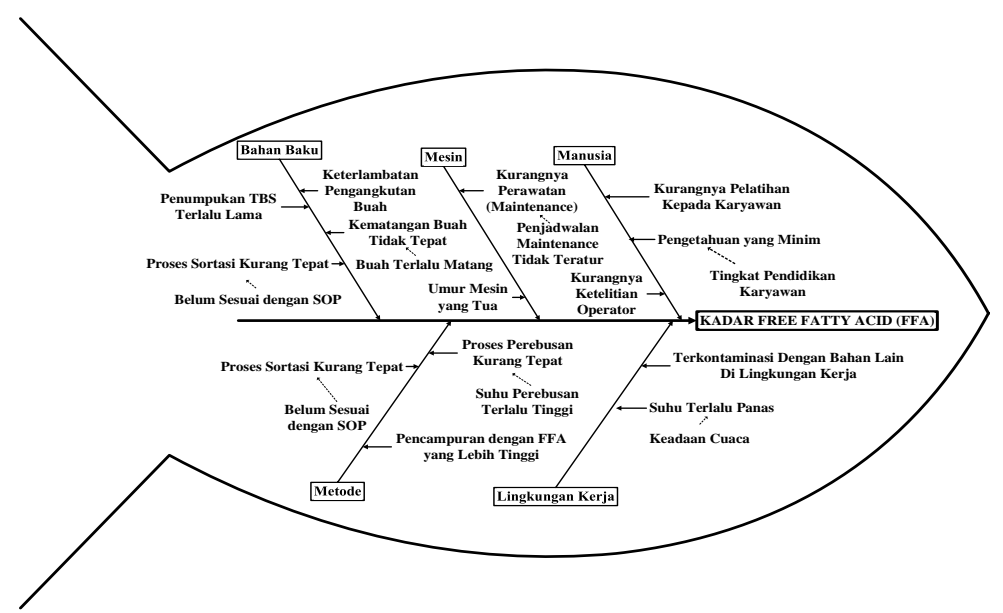

Gambar 3.4. Fishbone Kecacatan FFA

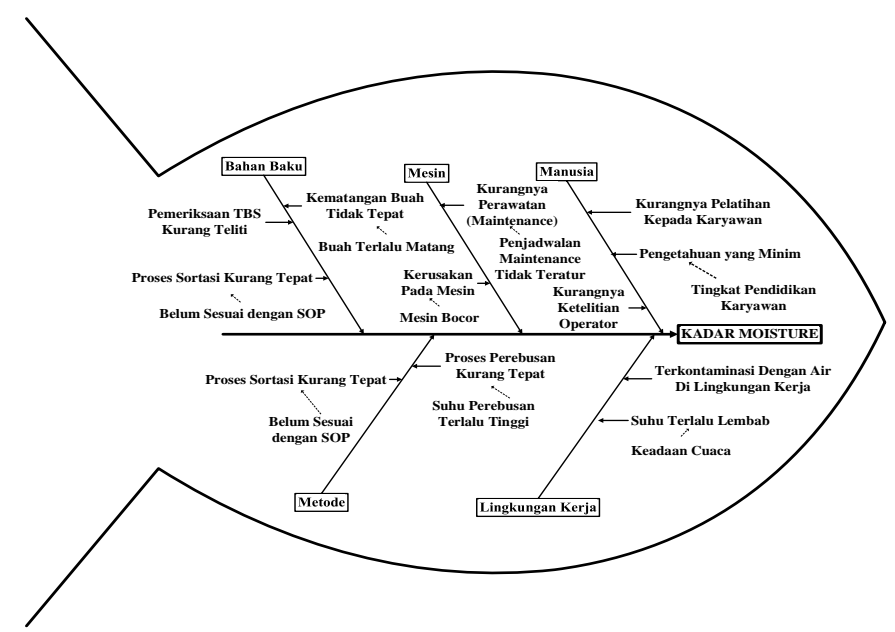

Gambar 3.5. Fishbone Kecacatan Moisture

(Where), Kapan (When), dan

3. Memberikan Usulan Perbaikan

Bagaimana (How).

Usulan perbaikan yang diberikan dapat dilakukan dengan analisis $5 \mathrm{~W}+1 \mathrm{H}$. Analisis $5 \mathrm{~W}+1 \mathrm{H}$ ini dilakukan dengan cara yaitu mengidentifikasi dan menganalisis permasalahan yang sedang terjadi serta menjabarkan mengenai maksud dari $5 \mathrm{~W}+1 \mathrm{H}$ tersebut berdasarkan pokok-pokok identifikasi Apa (What), Siapa (Who), Mengapa (Why), Dimana

b. Tahapan Do (Melaksanakan) 
Tabel 3.5. Rencana Perbaikan FFA

\begin{tabular}{|c|c|c|c|c|c|c|}
\hline No & Masalah & $\begin{array}{l}\text { Penyebab } \\
\text { Dominan }\end{array}$ & Rencana Perbaikan & Tujuan & $\begin{array}{c}\text { Perbaikan Yang } \\
\text { Dilakukan }\end{array}$ & Lokasi \\
\hline \multirow{3}{*}{1} & \multirow{3}{*}{$\begin{array}{c}\text { Kenaikan Kadar } \\
\text { Asam Lemak } \\
\text { Bebas } \\
\text { (Free Fatty Acid) }\end{array}$} & \begin{tabular}{|l} 
1. Proses \\
Gradingsoottasi \\
Kurang Tepat
\end{tabular} & $\begin{array}{l}\text { Melakukan grading } \\
\text { langsung pada saat } \\
\text { TBS datang, tanpa } \\
\text { harus ditumpuk }\end{array}$ & $\begin{array}{l}\text { Agar tidak terjadi } \\
\text { penumpukan TBS } \\
\text { yang dapat } \\
\text { menaikkan kadar } \\
\text { FFA }\end{array}$ & 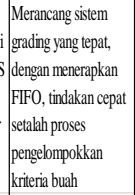 & Unit Grading \\
\hline & & \begin{tabular}{|l} 
2. Ketelilian \\
Operator/Karyawan \\
yang Minim
\end{tabular} & \begin{tabular}{|l|} 
Melakukan \\
pengawasan lebih \\
ketat dan memberikan \\
pemahaman
\end{tabular} & \begin{tabular}{|l|} 
Agar tidak terjadi \\
kesalhhan baik \\
saat pemilihan \\
buah/sortasi \\
maupun saat di \\
produksi
\end{tabular} & $\begin{array}{l}\text { Memberikan } \\
\text { pemahaman dan } \\
\text { melakukan } \\
\text { pengawasan kepada } \\
\text { operatorkikaryawan }\end{array}$ & $\begin{array}{c}\text { Unit } \\
\text { Grading dan } \\
\text { Unit } \\
\text { Produksi }\end{array}$ \\
\hline & & $\begin{array}{l}\text { 3. Kematangan TBS } \\
\text { yang Tidak Sesuai }\end{array}$ & \begin{tabular}{|l|} 
Melakukkan pendataan \\
waktu pengangkutan \\
TBS di \\
lapanganperkebunan \\
melalhi supir sehingga \\
dapat diklasiifikasi \\
buah sesuai fraksi \\
perusahaan
\end{tabular} & $\begin{array}{l}\text { Agar mengurangi } \\
\text { tingginya kadar } \\
\text { FFA akibat TBS } \\
\text { yang terlalu } \\
\text { matang }\end{array}$ & $\begin{array}{l}\text { merancang pendataan } \\
\text { kepada supir mengenai } \\
\text { waktu pengangkutan } \\
\text { TBS di lapangan }\end{array}$ & Unit Grading \\
\hline
\end{tabular}

Tabel 3.6. Rencana Perbailan Moisture

\begin{tabular}{|c|c|c|c|c|c|c|}
\hline No & Masalah & $\begin{array}{l}\text { Penyebab } \\
\text { Dominan }\end{array}$ & $\begin{array}{l}\text { Rencana } \\
\text { Perbaikan }\end{array}$ & Tujuan & $\begin{array}{c}\text { Perbaikan yang } \\
\text { Dilakukan }\end{array}$ & Lokasi \\
\hline \multirow{5}{*}{1} & \multirow{5}{*}{$\begin{array}{l}\text { Kenaikan } \\
\text { Kadar Air } \\
\text { (Moisture) }\end{array}$} & $\begin{array}{l}\text { 1. Proses } \\
\text { Grading/sortasi } \\
\text { Kurang tepat }\end{array}$ & $\begin{array}{l}\text { Melakukan grading } \\
\text { langsung pada saat } \\
\text { TBS datang, tanpa } \\
\text { harus ditumpuk }\end{array}$ & $\begin{array}{l}\text { Agar tidak terjadi } \\
\text { penumpukan TBS } \\
\text { yang dapat } \\
\text { menaikkan kadar } \\
\text { Moisture }\end{array}$ & $\begin{array}{l}\text { Merancang sistem grading } \\
\text { yang tepat, dengan } \\
\text { menerapkan FIFO, } \\
\text { tindakan cepat setalah } \\
\text { proses pengelompokkan } \\
\text { kriteria buah }\end{array}$ & Unit Grading \\
\hline & & $\begin{array}{l}\text { 2. Suhu } \\
\text { dilapangan kerja } \\
\text { lembab }\end{array}$ & $\begin{array}{l}\text { memastikan suhu } \\
\text { lapangan kerja } \\
\text { sesuai dan tidak } \\
\text { terlalu lembab }\end{array}$ & $\begin{array}{l}\text { Agar tidak terjadi } \\
\text { penambahan air } \\
\text { didalam TBS }\end{array}$ & $\begin{array}{l}\text { Memastikan kondisi } \\
\text { lapangan agar tidak } \\
\text { lembab }\end{array}$ & Unit Grading \\
\hline & & $\begin{array}{l}\text { 3. Ketelitian } \\
\text { operator/karyaw } \\
\text { an yang minim }\end{array}$ & $\begin{array}{l}\text { Melakukan } \\
\text { pengawasan lebih } \\
\text { ketat dan } \\
\text { memberikan } \\
\text { pemahaman }\end{array}$ & \begin{tabular}{|l|} 
Agar tidak terjadi \\
kesalahan baik saat \\
pemilihan \\
buah/sortasi maupun \\
saat di produksi \\
\end{tabular} & $\begin{array}{l}\text { Memberikan pemahaman } \\
\text { dan melakukan } \\
\text { pengawasan kepada } \\
\text { operator/karyawan }\end{array}$ & $\begin{array}{c}\text { Unit Grading } \\
\text { dan Unit } \\
\text { Produksi }\end{array}$ \\
\hline & & $\begin{array}{l}\text { 4. Kematangan } \\
\text { TBS yang tidak } \\
\text { sesuai }\end{array}$ & \begin{tabular}{|l} 
Melakukan \\
pendataan waktu \\
pengangkutan TBS \\
di \\
lapangan/perkebuna \\
n melalui supir \\
sehingga dapat \\
diklasifikasi buah \\
sesuai fraksi \\
perusahaan
\end{tabular} & $\begin{array}{l}\text { Agar mengurangi } \\
\text { tingginya kadar } \\
\text { Moisture akibat } \\
\text { TBS yang terlalu } \\
\text { matang }\end{array}$ & $\begin{array}{l}\text { Merancang pendataan } \\
\text { kepada supir mengenai } \\
\text { waktu pengangkutan TBS } \\
\text { di lapangan }\end{array}$ & Unit Grading \\
\hline & & $\begin{array}{l}\text { 5. Temperatur } \\
\text { pada perebusan } \\
\text { yang tidak sesuai }\end{array}$ & \begin{tabular}{|l|} 
Melakukan \\
pengawasan oleh \\
operator mengenai \\
temperatur saat \\
perebusan
\end{tabular} & $\begin{array}{l}\text { Menjaga kadar air } \\
\text { tetap stabil }\end{array}$ & $\begin{array}{l}\text { Melakukan pengawasan } \\
\text { oleh operator pada saat } \\
\text { proses perebusan }\end{array}$ & $\begin{array}{c}\text { Unit } \\
\text { Produksi }\end{array}$ \\
\hline
\end{tabular}

\section{c. Tahapan Check (Evaluasi)}

Setelah dilakukannya usulan perbaikan untuk menurunkan tingginya kadar FFA dan Moisture mutu Crude Palm Oil (CPO), maka selanjutnya adalah tahapan Check atau evaluasi. Pemeriksaan hasil perbaikan dapat dilihat pada tabel berikut ini:

Tabel 3.7. Data Perbaikan CPO 


\begin{tabular}{|c|c|c|c|c|c|}
\hline No & Masalah & $\begin{array}{c}\text { Perbaikan Yang } \\
\text { Dilakukan }\end{array}$ & $\begin{array}{c}\text { Waktu } \\
\text { Perbaikan } \\
\end{array}$ & $\begin{array}{c}\text { Waktu } \\
\text { Pengamatan }\end{array}$ & Hasil \\
\hline 1 & $\begin{array}{c}\text { Kenaikan } \\
\text { Kadar } \\
\text { Asam } \\
\text { Lemak } \\
\text { Bebas } \\
\text { (FFA) }\end{array}$ & $\begin{array}{lr}\text { Melakukan } & \text { grading } \\
\text { tanpa harus ditumpuk } \\
\text { dahulu, retelah } \\
\text { pemilihan makan TBS } \\
\text { langsung dimasukkan } \\
\text { ke dalam Loading } \\
\text { Ramp }\end{array}$ & $\begin{array}{l}10 \text { Oktober } \\
2020\end{array}$ & $\begin{array}{l}2 \text { kali } \\
\text { pengolahan } \\
\text { produksi } \\
\text { minyak sawit }\end{array}$ & $\begin{array}{l}\text { Setelah dilakukan } \\
\text { proses grading yang } \\
\text { tepat, maka terjadi } \\
\text { penurunan kadar } \\
\text { FFA }\end{array}$ \\
\hline 2 & $\begin{array}{l}\text { Kenaikan } \\
\text { Kadar } \\
\text { Air } \\
\text { (Moisture } \\
\text { ) }\end{array}$ & $\begin{array}{l}\text { Memastikan operator } \\
\text { menjaga } \\
\text { temperature/suhu } \\
\text { perebusan. }\end{array}$ & $\begin{array}{l}5 \text { Oktober } \\
2020\end{array}$ & 1 minggu & $\begin{array}{lr}\text { Pengawasan } & \text { oleh } \\
\text { operator } & \text { dalam } \\
\text { memantau } & \\
\text { temperatur perebusan } \\
\text { dan memastikan } \\
\text { lingkungan } & \text { tidak } \\
\text { lembab } & \text { dengan } \\
\text { melakukan } & \\
\text { pendataan } & \text { akan } \\
\text { menurunkan } & \text { kadar } \\
\text { moisture dan } & \end{array}$ \\
\hline
\end{tabular}

Berdasarkan hasil pengamatan terhadap

Berikut adalah tabel hasil pemeriksaan setelah dilakukannya proses grading usulan. Data berikut hanya dapat dilakukan oleh perusahaan 2 kali pengolahan dan pengujian 2 kali sampel yaitu sebagai berikut:

Tabel 3.8. Data Usulan Pengujian Sampel CPO

\begin{tabular}{|c|c|c|c|}
\hline Waktu & $\begin{array}{c}\text { Pengujian } \\
\text { Sampel }\end{array}$ & $\begin{array}{c}\text { Kadar } \\
\text { Asam } \\
\text { Lema } \\
\mathrm{k} \\
\text { Bebas } \\
\text { (FFA) }\end{array}$ & $\begin{array}{c}\text { Kadar } \\
\text { Air } \\
\text { (Moistur } \\
\text { e) }\end{array}$ \\
\hline $\begin{array}{c}\text { Sabtu, } \\
10 \\
\begin{array}{c}\text { Oktober } \\
2020\end{array}\end{array}$ & Sampel 1 & 3.23 & 0.14 \\
\cline { 2 - 4 } & Sampel 2 & 3.03 & 0.15 \\
\hline
\end{tabular}

d. Tahapan Action (Tindak Lanjut) hasil penerapan yang telah dilakukan, maka terdapat beberapa hal yang harus dilakukan yaitu sebagai berikut:

1. Mengoptimalkan proses grading/sortasi yang tepat dengan tindakan cepat dan sigap sebagai upaya pencegahan terjadinya penumpukan TBS di unit grading.

2. Melakukan pendataan waktu lamanya buah diangkut dari lapangan melalui supir truk.

3. Mengadakan sosialisasi terkait usulan perbaikan yang telah diajukan.

4. Melakukan pengawasan dan pengontrolan mengenai suhu saat proses perebusan.

\section{Simpulan}


1. Penyebab kecacatan pada parameter pengujian mutu Crude Palm Oil (CPO) memiliki beberapa faktor yaitu :

a. Faktor Man (Manusia) sebagai operator atau karyawan yang mengontrol mesin dan melaksanakan proses produksi.

b. Faktor Mesin yang digunakan sebagai alat pendukung selama proses produksi berlangsung.

c. Faktor Bahan Baku yang berguna sebagai input dan faktro terpenting dalam menjalankan produksi perusahaan ini.

d. Faktor Metode menjadi cara atau sistem yang dilakukan selama menjalankan prosedur yang ada.

e. Faktor Lingkungan Kerja menjadi kondisi lapangan kerja yang menjadi pendukung dalam melaksanakan proses produksi.

2. Usulan perbaikan atau rekomendasi yang diberikan mengenai kecacatan parameter CPO yaitu dengan memperhatikan proses grading/sortasi yang tepat dengan keadaan siap siaga untuk mengurangi terjadinya penumpukan yang dapat menaikkan kadar asam lemak bebas (FFA), memantau suhu/temperatur pada saat perebusan disesuaikan dengan Standar Operasional Prosedur (SOP) yang ada pada perusahaan tersebut untuk mencegah terjadinya kenaikan kadar air (moisture).

\section{DAFTAR PUSTAKA}

[1] Al Fakhri, Faiz. 2010. Analisis Pengendalian Kualitas Produksi di PT. Masscom Grahpy Dalam Upaya Mengendalikan Tingkat Kerusakan Produk Menggunakan Alat Bantu Statistik. Semarang.

[2] Deming, W. Edwards. 2005. Total Quality Management. Jakarta. Penerbit: Rineka Cipta.

[3] Gaspersz, V. 2001. Total Quality Management. Jakarta: PT. Gramedia Pustaka Utama.

[4] Irwan dan Haryono, Didi. 2015. Pengendalian Kualitas Statistik (Pendekatan Teoritis dan Aplikatif). Bandung: Alfabeta.

[5] Ibrahim, Buddy. 2000. TQM (Total Quality Management: Panduan Menghadapi Persaingan Global. Djambatan. Jakarta.

[6] Sulaeman. 2014. Analisa Pengendlaian Kualitas Untuk Mengurangi Produk Cacat Speedometer Mobil Dengan Menggunakan Metode QCC di PT INS. Jurnal Pasti, VIII (1), 71-95.

[7] Tarihoran.N,Siregar.K,Ishak.A. 2013. Analisa Pengendalian Kualitas Pada Proses Perebusan Dengan Menerapkan QCC (Quality Control Circle) Di PT.XYZ. Jurnal Online Teknik Industri FT USU Vol 3,No.1. 